\section{Reaction to Plasmodiophora brassicae Pathotype 6 in Lines of Brassica Vegetables, Wisconsin Fast Plants, and Canola}

\author{
Kalpana K.C. Adhikari and Mary Ruth McDonald ${ }^{1}$ \\ Department of Plant Agriculture, University of Guelph, 50 Stone Road East, \\ Guelph, Ontario, N1G 2W1, Canada
}

\author{
Bruce D. Gossen \\ Agriculture and Agri-Food Canada, 107 Science Place, Saskatoon, \\ Saskatchewan, S7N 0X2, Canada
}

Additional index words. clubroot, host resistance, napa cabbage, Rapid Cycling Brassica Collection

\begin{abstract}
Field trials were conducted from 2008 to 2010 to assess the disease reaction to clubroot, caused by Plasmodiophora brassicae Woronin, in selected lines of Brassica spp., including short-season vegetable crops [Shanghai pak choy (B. rapa subsp. Chinensis var. communis)], Chinese flowering cabbage (B. rapa subsp. Chinensis var. utilis), and napa cabbage (B. rapa subsp. Pekinensis), the Rapid Cycling Brassica Collection (RCBC), also known as Wisconsin Fast Plants, and spring canola (B. napus). The trials were conducted on naturally infested soil with $P$. brassicae at the Muck Crops Research Station in Ontario, Canada, where pathotype 6 is predominant. Clubroot incidence and severity were higher in 2008 and 2010 compared with 2009. The lines of Shanghai pak choy and Chinese flowering cabbage were highly susceptible to clubroot, but each of the clubrootresistant cultivars of napa cabbage, 'Deneko', 'Bilko', and 'Yuki', was highly resistant to pathotype 6. Among the RCBC lines, $B$. carinata and $B$. juncea were highly susceptible and could be used as susceptible models for further studies. Two RCBC lines, B. napus and $R$. sativus, were resistant to pathotype 6 . Two of the canola cultivars, $46 \mathrm{~A} 76$ and 46A65, were susceptible, but two others, '45H21' and 'Invigor 5020LL', were highly resistant to pathotype 6 . This difference in response can be exploited in future studies of clubroot reaction in canola.
\end{abstract}

Clubroot, caused by the soilborne protist Plasmodiophora brassicae Woronin, has long been recognized as an important disease of Brassica vegetable crops worldwide, and most Brassica spp. are highly susceptible. Management of clubroot is a challenge where Brassica crops are grown frequently because resting spores can survive for many years and are readily disseminated through movement of infested soil (Karling, 1968; Wallenhammar, 1996).

Development and proliferation of P. brassicae in susceptible hosts cause disorganized growth (hyperplasia and hypertrophy) of the root tissues that disrupts uptake and transport of water and nutrients (Mithen and Magrath, 1992). Plants become wilted and stunted, and yield can be reduced when symptoms are

Received for publication 29 Nov. 2011. Accepted for publication 13 Jan. 2012.

Funding was provided by the Clubroot Mitigation Initiative of Agriculture and Agri-Food Canada and the Ontario Ministry of Agriculture, Food and Rural Affairs and University of Guelph Partnership. We thank Abhinandan Deora and Kalpana Sharma for reviewing the manuscript before submission.

${ }^{1}$ To whom reprint requests should be addressed; e-mailmrmcdona@uoguelph.ca.
(Williams, 1966), and most sources of resistance are pathotype-specific (Diederichsen et al., 2009).

Clubroot has recently become a major issue for canola (B. napus L.) producers in Canada because of its rapid spread since it was first reported on canola in western Canada in 2003 (Tewari et al., 2005). The first clubroot-resistant canola cultivar registered in Canada, '45H29', was released by Pioneer Hi-Bred for the 2010 growing season. Resistance in this line is effective against pathotypes 3 and 5 (Cao et al., 2009) and to pathotype 6 (unpublished), but the durability of this resistance is not yet known.

A range of studies on clubroot has been conducted using Arabidopsis as a model crop, but for certain studies, it would be useful to assess a model crop in the genus Brassica with an architecture and pattern of development that was more similar to commercial crops. Plants in the RCBC, also known as Wisconsin Fast Plants, were developed by selecting and crossing early-flowering lines of Brassica spp. The result is a collection of lines with a short life cycle (36-48 d) and small stature (Williams and Hill, 1986). Their small size and rapid development make them excellent candidates for use as model crops in studies of clubroot. Screening selected RCBC lines against $P$. brassicae could identify lines that could be used for research where space is limited (e.g., under controlled conditions) and results from these lines could be obtained more quickly than with conventional crop cultivars. Similarly, the small stature and rapid development of several Asian Brassica vegetable crops such as Shanghai pak choy [Brassica rapa L. subsp. Chinensis (Rupr.) var. communis Tsen and Lee] and Chinese flowering cabbage [B. rapa subsp. Chinensis (Rupr.) var. utilis Tsen and Lee] might also make them suitable as model crops for studies of clubroot.

The main objective of this study was to identify the reaction of selected lines of several crops to the predominant pathotype of P. brassicae in Ontario (Cao et al., 2009; Reyes et al., 1974) [pathotype 6, as classified on the differential set of Williams (Williams, 1966)] or ECD 16/0/14 based on the European Clubroot Differential set (Buczacki et al., 1975). In addition, we sought to identify RCBC lines that might have a role as model crops for vegetables, canola, and other commercial crops in future studies of clubroot and to identify clubroot-resistant and susceptible Brassica lines that could be used in the wide range of host-pathogen interaction studies.

\section{Materials and Methods}

A selection of Brassica species and cultivars was evaluated under field conditions for clubroot incidence and severity on an organic soil (Hemisol pH 6.3-6.7, 69\% to 75\% organic matter) naturally infested with $P$. brassicae pathotype 6 . The trials were conducted at the Muck Crops Research Station (MCRS) of the University of Guelph, Holland Marsh, Ontario, Canada (lat. $44^{\circ} 15^{\prime} \mathrm{N}$, long. $79^{\circ} 35^{\prime} \mathrm{W}$ ) 
in 2008, 2009, and 2010 at sites within $30 \mathrm{~m}$ of each other.

The study examined host reaction to clubroot in selected lines of RCBC, Asian vegetables, and canola. In 2008, the RCBC lines (RCBC, Madison, WI) selected for the study were: Brassica carinata (L.) A. Braun (genome designation, $\mathrm{BCbbcc}$; haploid chromosome number, bc $=17), B$. juncea (L.) Czern $(\mathrm{ABaabb}, \mathrm{ab}=18)$, B. napus L. (ACaacc, $\mathrm{ac}=19)$, B. nigra (L.) W.D.J. Koch (Bbb, b = 8), B. oleracea L. $(\mathrm{Ccc}, \mathrm{c}=9), B$. rapa L. (Aaa, $\mathrm{a}=10$ ) astroplant, $B$. rapa standard rapid cycling, B. rapa atrazine resistant, and Raphanus sativus L. (radish). The RCBC lines were selected to represent the six most economically important and widely grown Brassica crops. The three lines of $B$. rapa were included because some of the phenotype/genotype characters are different among these lines and there was a report of resistance to clubroot associated with triazine-resistant canola (Vigier et al., 1989). Raphanus sativus, which is a close relative of the genus Brassica (Williams and Hill, 1986), was included because transfer of genes for clubroot resistance from $R$. sativus to a Brassica spp. through somatic hybridization has been reported (Hagimori et al., 1992). The Asian vegetables included two lines of Shanghai pak choy: a generic line (Chan Man Hop Seeds Co., Hong Kong) and cv. Mei Qing Choi (Stokes Seeds Ltd., Ontario, Canada), two lines of Chinese flowering cabbage: generic (Chan Man Hop Seeds Co.) and cv. Tsoi-sim (Stokes Seeds Ltd.), and three cultivars of napa cabbage: 'Deneko' and 'Bilko' (Bejo Seeds Inc., New York, NY) and 'Yuki' (Stokes Seeds Ltd.). Shanghai pak choy, which is highly susceptible to $P$. brassicae (McDonald and Westerveld, 2008), was used as the susceptible control in these trials. The trials also included three canola cultivars from Pioneer Hi-Bred, Ontario, Canada: '46A76 IMI' (imidazolinone-tolerant), '46A65' (conventional), and '45H21 RR' (Roundup Ready hybrid), and one from Bayer Crop Science, Ontario, Canada: 'Invigor 5020 LL' (Liberty Link). In 2009, the generic lines of Shanghai pak choy and Chinese flowering cabbage were dropped from the study because of the scarcity of the seeds, and they also exhibited a similar reaction to $P$. brassicae as the respective named cultivars Mei Qing Choi and Tsoi-sim. In addition, two of the napa cabbage cultivars (Bilko and Yuki) were not included in 2009 because they were resistant to clubroot and similar to 'Deneko'. Several additional lines were not included in the study in 2010 because their interaction with P. brassicae was similar to that of other lines in the trial and consistent over the previous 2 years: RCBC lines B. nigra, B. rapa astroplant and atrazine-resistant, and $R$. sativus, and canola '46A65' and 'Invigor 5020 LL'. Trials conducted in 2008 and 2009 confirmed that all of the napa cabbage cultivars were resistant, so they were not included in the trial in 2010. 'Tsoi-sim' was also dropped in 2010 because of poor seed germination compared with 'Mei Qing Choi'. Also, trials in previous years concluded that 'Mei Qing Choi' was more susceptible than 'Tsoi-sim'.

The trials were established by direct seeding on 9 July 2008, 9 July 2009, and 3 Aug. 2010. These seeding dates were selected to ensure that seedling germination and establishment occurred during the warmest portion of summer, when there is a high risk of clubroot development (McDonald and Westerveld, 2008). The plots were arranged in a randomized complete block design with four replications. In 2008, the amount of available seed of the RCBC lines was limited, so they were seeded in two 1.5 -m-long rows with three replications. The other lines were seeded in single 5.4-m-long rows with $40 \mathrm{~cm}$ between rows. In 2009 and 2010, each plot consisted of two 3-m-long rows.

Plants of the RCBC lines, Shanghai pak choy, Chinese flowering cabbage, and canola cultivars, were dug or pulled 6 weeks after seeding. Although still immature, the canola plants were assessed at this time because this study was mainly focused on incidence and severity of clubroot during vegetative crop growth. However, the napa cabbage cultivars were harvested 10 weeks after seeding, at their optimum harvest maturity. All of the plants in each plot (23-86 plants) were harvested for clubroot assessment in 2008 and 2009. In 2010, 25 plants per plot were assessed. The roots were cleaned and then assessed for clubroot incidence and severity. Clubroot severity was rated using a $0-3$ scale (Kuginuki et al., 1999), where: $0=$ no galling, 1 = a few small galls (small galls on less than one-third of the root), 2 = moderate galling (small to medium-sized galls on onethird to two-thirds of the root), and $3=$ severe galling (medium to large-sized galls on greater than two-thirds of the root). A disease severity index (DSI) was calculated using the following equation (Kobriger and Hagedorn, 1983):

\section{DSI $=$}

$\sum[($ class no. $)($ no. plants in each class $)]$

$\overline{\text { (total no. plants per sample)(no. classes }-1)}$ $\times 100$

Weather parameters were measured at a weather station (Campbell Scientific, Edmonton, Alberta, Canada) located at the MCRS within $100 \mathrm{~m}$ of the experimental plots. Air temperatures were measured using a HMP35C probe, soil temperatures at $5-\mathrm{cm}$ depth using a Model 107 probe, and rainfall data using a tipping-bucket rain gauge. Temperatures (air and soil) and rainfall data were recorded every hour using a CR21X data logger. Daily maximum, minimum, and mean temperatures and total rainfall were calculated for the growing period of the crops in each trial.

Statistical analyses were performed using SAS Version 9.1 (SAS Institute, Cary, NC). A mixed-model analysis of variance of the data in each trial was conducted using PROC MIXED with species/lines as the fixed effect and year and replication as random effects.
The data set for each trial was tested for normality using the Shapiro-Wilk test of residuals, and outliers were identified using Lund's test of standardized residuals (Lund, 1975). No outliers were found in any data set. Mean separation was conducted using Tukey's multiple mean comparison test. Differences were significant at $P \leq 0.05$ unless otherwise noted.

\section{Results and Discussion}

The RCBC lines of R. sativus and B. napus were resistant to $P$. brassicae at this site and $B$. oleracea was moderately susceptible (Table 1). Other RCBC lines were highly susceptible, especially $B$. carinata and $B$. juncea, which had levels of clubroot similar to the highly susceptible control, Shanghai pak choy (Table 1). There were no differences in clubroot incidence and severity among the lines of $B$. rapa, which indicates that resistance to atrazine is not consistently related to resistance to clubroot, as reported previously (Vigier et al., 1989). To our knowledge, this is the first study to evaluate the reaction of RCBC lines to $P$. brassicae. However, there was a study on resistance gene selection to Albugo candida in rapid cycling $B$. campestris lines (Edwards and Williams, 1987). Use of these highly susceptible short-generation RCBC lines as model crops could reduce the duration of many studies of this host-pathogen interaction relative to standard lines of the same crop. Their small stature would also facilitate studies in situations in which space is restricted such as containment facilities. The RCBC seeds are quite expensive $(\$ 10 / 100$ seeds) but this cost is small compared with the daily cost of using growth cabinets and containment facilities.

Two lines of Shanghai pak choy, a generic line and 'Mei Qing Choi', were included in the trial in 2008 because seed of the generic line that had been used in previous studies (e.g., McDonald and Westerveld, 2008) had become scarce, but seed of a named cultivar had become available. The same situation with seed availability also occurred for the lines of Chinese flowering cabbage (generic and 'Tsoi-sim'). For both crops, plant phenology and development were similar in the two lines (data not shown), and both lines were highly susceptible to $P$. brassicae (Table 1). Therefore, the generic cultivars were dropped from the trial in 2009. We conclude that the named cultivars have a similar reaction to $P$. brassicae pathotype 6 to that of the generic lines used in previous studies and so can be used as replacements for the generic lines in subsequent studies. Shanghai pak choy has potential as a susceptible model crop for studies on clubroot because of its small size and susceptibility, but it does not go to seed as rapidly as the RCBC lines.

All three cultivars of napa cabbage, each of which is marketed as resistant to clubroot, were highly resistant at this site in 2008 . 'Bilko' and 'Yuki' were dropped from the study in 2009 because they had the same 
Table 1. Clubroot incidence (CI, \%) and severity [disease severity index (DSI)] on lines of Brassica spp. grown in soil infested with Plasmodiophora brassicae at the Holland Marsh, Ontario, Canada, 2008-2010.

\begin{tabular}{|c|c|c|c|c|c|c|}
\hline \multirow[b]{2}{*}{ Crops/species and line } & \multicolumn{2}{|c|}{2008} & \multicolumn{2}{|c|}{2009} & \multicolumn{2}{|c|}{2010} \\
\hline & $\mathrm{CI}$ & DSI & $\mathrm{CI}$ & DSI & $\mathrm{CI}$ & $\overline{\mathrm{DSI}}$ \\
\hline \multicolumn{7}{|l|}{ Rapid cycling Brassica crops } \\
\hline Brassica carinata & $97 \mathrm{f}^{\mathrm{z}}$ & $97 \mathrm{f}$ & $45 \mathrm{c}$ & $19 \mathrm{c}$ & $85 \mathrm{c}$ & $82 \mathrm{c}$ \\
\hline B. nigra & 89 ef & 66 def & $3 \mathrm{a}$ & $1 \mathrm{a}$ & - & - \\
\hline B. rapa, astroplant & 84 ef & 69 ef & $2 \mathrm{a}$ & $1 \mathrm{a}$ & - & - \\
\hline B. rapa, standard & 82 ef & 74 ef & $19 \mathrm{abc}$ & $8 \mathrm{abc}$ & $87 \mathrm{c}$ & $77 \mathrm{c}$ \\
\hline B. rapa, atrazine-resistant & 75 def & 67 ef & $8 \mathrm{ab}$ & $7 \mathrm{ab}$ & - & - \\
\hline B. napus & $4 a b$ & $1 \mathrm{a}$ & $1 \mathrm{a}$ & $0.4 \mathrm{a}$ & $4 \mathrm{a}$ & $3 \mathrm{a}$ \\
\hline \multicolumn{7}{|l|}{ Asian vegetables } \\
\hline \multicolumn{7}{|c|}{ Shanghai pak choy (B. rapa. subsp. Chinensis var. communis) } \\
\hline Generic & 89 ef & 71 ef & - & - & - & - \\
\hline Mei Qing Choi & 80 ef & $56 \mathrm{cde}$ & $9 \mathrm{ab}$ & $3 a b$ & $89 \mathrm{c}$ & $64 \mathrm{bc}$ \\
\hline \multicolumn{7}{|c|}{ Chinese flowering cabbage (B. rapa subsp. Chinensis var. utilis) } \\
\hline Bilko & $3 \mathrm{ab}$ & $3 \mathrm{a}$ & - & - & - & - \\
\hline Yuki & $1 \mathrm{ab}$ & $1 \mathrm{a}$ & - & - & - & - \\
\hline \multicolumn{7}{|l|}{ Canola (B. napus) } \\
\hline $46 \mathrm{~A} 76$ & 52 cde & $44 \mathrm{~b}-\mathrm{e}$ & $11 \mathrm{ab}$ & $4 \mathrm{ab}$ & $81 \mathrm{c}$ & $73 \mathrm{c}$ \\
\hline $46 \mathrm{~A} 65$ & $33 \mathrm{abc}$ & $26 a-d$ & $4 \mathrm{a}$ & $1 \mathrm{a}$ & - & - \\
\hline Invigor $5020 \mathrm{LL}$ & $0 \mathrm{a}$ & $0 \mathrm{a}$ & $0 \mathrm{a}$ & $0 \mathrm{a}$ & - & - \\
\hline $45 \mathrm{H} 21$ & $0 \mathrm{a}$ & $0 \mathrm{a}$ & $0 \mathrm{a}$ & $0 \mathrm{a}$ & $7 \mathrm{a}$ & $3 \mathrm{a}$ \\
\hline
\end{tabular}

${ }^{\mathrm{z}}$ Means within a column followed by the same letter do not differ based on Tukey's test at $P=0.05$.

reaction to clubroot as 'Deneko'. This observation supports a previous report of assessment of cv. Bilko under controlled conditions, in which this cultivar was highly resistant to each of the pathotypes of $P$. brassicae that occur in Canada (Hasan, 2010). There was no clubroot development in 'Deneko' in 2009, which confirmed the result from 2008 when there was a little disease development. Therefore, 'Deneko' was dropped from the study in 2010.

Among the four canola cultivars, 46A76 was highly susceptible to pathotype 6 in all 3 years of the study. Cultivar 46A65 had slightly lower clubroot incidence than '46A76' in 2008 but generally did not differ from ' 46 A 76 ' and so was dropped from the study in 2010 . Cultivars Invigor 5020LL and 45H21 were both highly resistant in 2008 and 2009, so 'Invigor 5020LL' was dropped from the study in 2010. It is interesting to note that a low level of clubroot (both incidence and severity) developed on '45H21' in 2010 (Table 1). This indicates that even a highly resistant line can develop low levels of clubroot when conditions are highly conducive for infection and pathogen development. Also, the canola cultivars Invigor $5020 \mathrm{LL}$ and $45 \mathrm{H} 21$, which are susceptible to pathotype 3 or ECD 16/15/12 (Strelkov et al., 2006) were resistant to pathotype 6 , so either line can be used to differentiate pathotype 6 from pathotype 3 .

Clubroot incidence and severity were higher in 2008 and 2010 than in 2009. There was a small line-by-year interaction, but the lines mostly exhibited a similar pattern of response across all 3 years (Table 1). Rainfall during the growing season over the 3 years of the study was quite consistent and adequate for crop growth, but temperatures during the early growing period of the crop were lower in $2009\left(17.9^{\circ} \mathrm{C}\right)$ than $2008\left(20.4^{\circ} \mathrm{C}\right)$ and $2012\left(21.1^{\circ} \mathrm{C}\right)$. The cool conditions in 2009 may have contributed to lower clubroot incidence and severity (Gossen et al., 2011). However, the low levels of clubroot in 2009 may also have resulted from low concentrations of resting spores of $P$. brassicae in that specific portion of the study site, although all of the trials were conducted within $30 \mathrm{~m}$ of each other. Later on, the overall spore concentration of $P$. brassicae in the research site was found to be $1 \times 10^{5}$ to $1.3 \times 10^{6} / \mathrm{g}$ of soil (M.T. Tesfaendrias, personal communication). Previous studies have demonstrated that root hair infection (Naiki et al., 1978) and clubroot severity (Hildebrand and McRae, 1998) increase with increasing spore load above a minimum threshold level for symptom development (Faggian and Strelkov, 2009). The distribution of clubroot within fields can be very patchy (Strelkov et al., 2007), and existing tests to assess the density of resting spores are too labor-intensive and time-consuming (Dhingra and Sinclair, 1985; Murakami et al., 2000) to be feasible when intensive sampling is required. A rapid and inexpensive test that could be used to quantify inoculum concentration at numerous points in a field would be very useful for identifying uniform areas for field trials as well as for various epidemiological studies.

In conclusion, the current study examined the reaction to $P$. brassicae pathotype 6 in a range of Brassica lines. Use of these lines as model crops could expedite a broad range of clubroot research on Brassica vegetables and canola. The RCBC lines of B. carinata and
$B$. juncea were highly susceptible to pathotype 6 , and lines of $R$. sativus and $B$. napus were highly resistant. These lines may be useful as model crops for studies such as host-pathogen interaction, seed yield in relation to disease severity, and for disease management trials. Additional studies with other pathotypes would be useful. This study confirmed that the cultivars of napa cabbage, 'Deneko', 'Bilko', and 'Yuki', were highly resistant to $P$. brassicae pathotype 6 . The susceptible canola cultivars 46A76 and 46A65 and resistant cultivars Invigor $5020 \mathrm{LL}$ and $45 \mathrm{H} 21$ can also be used for further studies on host-pathogen interaction.

\section{Literature Cited}

Adhikari, K.K.C. 2010. Effect of temperature, biofungicides and fungicides on clubroot of selected Brassica crops. MSc thesis, University of Guelph, Guelph, Ontario, Canada.

Buczacki, S.T., H. Toxopeus, P. Mattusch, T.D. Johnston, G.R. Dixon, and L.A. Hobolth. 1975. Study of physiologic specialization in Plasmodiophora brassicae: Proposals for attempted rationalization through an international approach. Trans. Br. Mycol. Soc. 65:295-303.

Cao, T., V.P. Manolii, S.F. Hwang, R.J. Howard, and S.E. Strelkov. 2009. Virulence and spread of Plasmodiophora brassicae [clubroot] in Alberta, Canada. Can. J. Plant Pathol. 31:321329.

Dhingra, O.D. and J.B. Sinclair. 1985. Basic plant pathology methods. CRC Press, Boca Raton, FL.

Diederichsen, E., M. Frauen, E.G.A. Linders, K. Hatakayema, and M. Hirai. 2009. Status and perspectives of clubroot resistance breeding in crucifer crops. J. Plant Growth Regul. 28:265281.

Dixon, G.R. 2006. The biology of Plasmodiophora brassicae Wor.-A review of recent advances. Acta Hort. 706:271-282. 
Dobson, R.L. and R.L. Gabrielson. 1983. Role of primary and secondary zoospores of Plasmodiophora brassicae in the development of clubroot in Chinese cabbage. Phytopathology 73:559561.

Donald, E.C. and I. Porter. 2009. Integrated control of clubroot. J. Plant Growth Regul. 28:289-303.

Edwards, M.C. and P.H. Williams. 1987. Selection for minor gene resistance to Albugo candida in rapid-cycling populations of Brassica campestris. Phytopathology 77:527-532.

Faggian, R. and S.E. Strelkov. 2009. Detection and measurement of Plasmodiophora brassicae. J. Plant Growth Regul. 28:282-288.

Gossen, B.D., K.K.C. Adhikari, and M.R. McDonald. 2011. Temperature influences both infection and development of clubroot under controlled conditions. Plant Pathol. (in press)

Hagimori, M., M. Nagaoka, N. Kato, and H. Yoshikawa. 1992. Production and characterization of somatic hybrids between the Japanese radish and cauliflower. Theor. Appl. Genet. 108: 819-824.

Hasan, M.J. 2010. Screening of Brassica germplasm for resistance to Plasmodiophora brassicae pathotypes prevalent in Alberta, Canada. MSc thesis, Department of Agricultural, Food and Nutritional Science, University of Alberta. Edmonton, Alberta, Canada.

Hildebrand, P.D. and K.B. McRae. 1998. Control of clubroot caused by Plasmodiophora brassicae with non-ionic surfactants. Can. J. Plant Pathol. 20:1-11.

Hirai, M. 2006. Genetic analysis of clubroot resistance in Brassica crops. Breed. Sci. 56:223-229.

Karling, J.S. 1968. The Plasmodiophorales. Hafner Publishing Company, Inc., New York, NY.

Kobriger, K.M. and D.J. Hagedorn. 1983. Determination of bean root rot potential in vegetable production fields of Wisconsin's Central Sands. Plant Dis. 67:177-178.

Kuginuki, Y., H. Yoshikawa, and M. Hirai. 1999. Variation in virulence of Plasmodiophora brassicae in Japan tested with clubroot-resistant cultivars of Chinese cabbage (Brassica rapa L. ssp. pekinensis). Eur. J. Plant Pathol. 105:327-332.

Lund, R.E. 1975. Tables for an approximate test for outliers in linear models. Techometrics 17 : 473-476.

McDonald, M.R. and S.M. Westerveld. 2008. Temperature prior to harvest influences the incidence and severity of clubroot on two Asian Brassica vegetables. HortScience 43:15091513.

Mitani, S., K. Sugimoto, H. Hayashi, Y. Takii, T. Ohshima, and N. Matsuo. 2003. Effects of cyazofamid against Plasmodiophora brassicae Woronin on Chinese cabbage. Pest Mgt. Sci. 59:287-293.

Mithen, R. and R. Magrath. 1992. A contribution to the life history of Plasmodiophora brassicae: Secondary plasmodia development in root galls of Arabidopsis thaliana. Mycol. Res. 96:877885.

Murakami, H., S. Tsushima, T. Akimoto, K. Murakami, I. Goto, and Y. Shishido. 2000. Effects of growing leafy daikon (Raphanus sativus) on populations of Plasmodiophora brassicae (clubroot). Plant Pathol. 49:584-589.

Murakami, H., S. Tsushima, Y. Kuroyanagi, and Y. Shishido. 2002. Reduction of resting spore density of Plasmodiophora brassicae and clubroot disease severity by liming. Soil Sci. Plant Nutr. 48:685-691.

Myers, D.F. and R.N. Campbell. 1985. Lime and the control of clubroot of crucifers: Effects of $\mathrm{pH}$, calcium, magnesium, and their interactions. Phytopatholology 75:670-673.

Naiki, T., K. Kageyama, and H. Ikegami. 1978. The relation of spore density of Plasmodiophora brassicae Wor. to the root hair infection and club formation in Chinese cabbage. (Studies on the clubroot of cruciferous plants II.) Ann. Phytopathological Soc. Jpn. 44:432-439.

Narisawa, K., K.T. Ohki, and T. Hashiba. 2000. Suppression of clubroot and Verticillium yellows in Chinese cabbage in the field by the root endophytic fungus, Heteroconium chaetospira. Plant Pathol. 49:141-146.
Peng, G., R. Lahlali, B.D. Gossen, S.F. Hwang, K.K. Adhikari, S.E. Strelkov, and M.R. McDonald 2011. Potential biological control of clubroot on canola and crucifer vegetable crops. Plant Pathol. 60:566-574.

Reyes, A.A., T.R. Davidson, and C.F. Marks. 1974. Races, pathogenicity and chemical control of Plasmodiophora brassicae in Ontario. Phytopathology 64:173-177.

Strelkov, S.E., V.P. Manolii, T. Cao, S. Xue, and S.F. Hwang. 2007. Pathotype classification of Plasmodiophora brassicae and its occurrence in Brassica napus in Alberta, Canada. J. Phytopathol. 155:706-712.

Strelkov, S.E., J.P. Tewari, E. Smith, and E. SmithDegenhardt. 2006. Characterization of Plasmodiophora brassicae populations from Alberta, Canada. Can. J. Plant Pathol. 28:467-474.

Suzuki, K., K. Sugimoto, H. Hayashi, and T. Komyoji. 1995. Biological mode of action of fluazinam, a new fungicide for Chinese cabbage clubroot. Phytopathol. Soc. Jpn. 61:395398 .

Tewari, J.P., S.E. Strelkov, D. Orchard, M. Hartman, R.M. Lange, and T.K. Turkington. 2005. Identification of clubroot of crucifers on canola (Brassica napus) in Alberta. Can. J. Plant Pathol. 27:143-144.

Vigier, B., M.S. Chiang, and D.J. Hume. 1989. Source of resistance to clubroot (Plasmodiophora brassicae Wor.) in triazine-resistant spring canola (rapeseed). Can. Plant Dis. Surv. 69:113-115.

Wallenhammar, A.C. 1996. Prevalence of Plasmodiophora brassicae in a spring oilseed rape growing area in central Sweden and factors influencing soil infestation levels. Plant Pathol. 45:710-719.

Williams, P.H. 1966. A system for the determination of races of Plasmodiophora brassicae that infect cabbage and rutabaga. Phytopathology 56:624-626.

Williams, P.H. and C.B. Hill. 1986. Rapid-cycling populations of Brassica. Sci. New Ser. 232: 1385-1389 